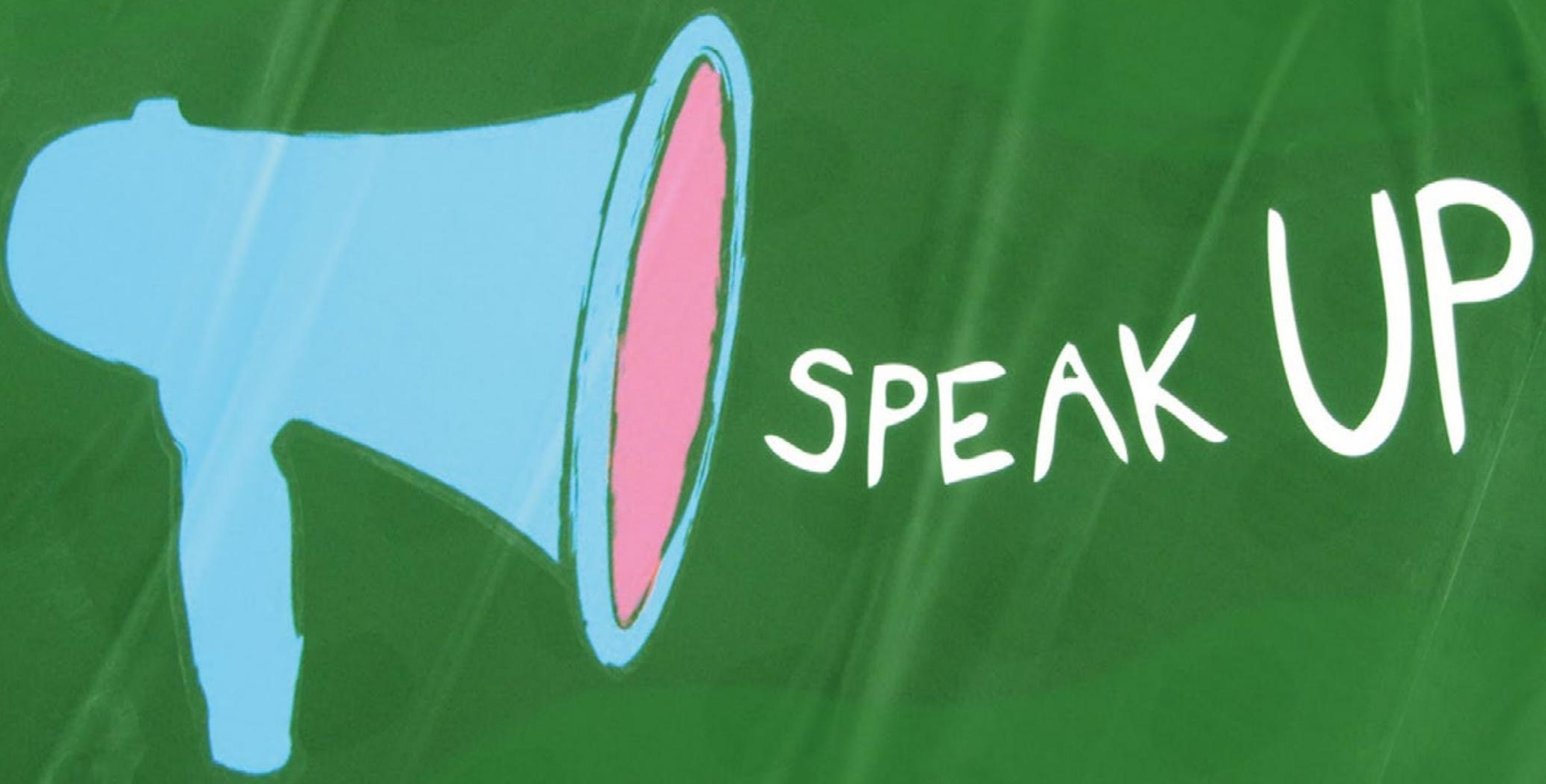

\title{
A MOTIVAÇÃO POR MEIO DA ORALIDADE NO APRENDIZADO DA LÍNGUA INGLESA
}

\section{RESUMO}

Este artigo se propõe a refletir sobre a motivação no ensino da oralidade da língua inglesa, no ensino fundamental da escola pública, e sobre o uso de jogos e atividades lúdicas, como incentivo na participação desses alunos. As aulas foram observadas e ministradas por bolsistas do Programa Institucional de Bolsa de Iniciação à Docência (PIBID), em uma turma da escola estadual Ary Parreiras, no bairro do Alecrim, em Natal-RN, durante o segundo bimestre de 2016. Com o objetivo de auxiliar na compreensão do conteúdo estudado em sala de aula, foram realizadas atividades com foco na prática de compreensão auditiva (listening) e produção oral (speaking). Os alunos foram incentivados a interagir e a cooperar entre si, de forma que até os mais tímidos participaram. Pôde-se observar um maior interesse dos alunos nas aulas de língua inglesa, bem como uma maior participação, consequências diretas do fator motivação.

Palavras-chave: Motivação. PIBID.

Escola pública. Ensino-aprendizagem de língua inglesa. Produção oral. 


\section{INTRODUÇÃO}

O ensino de inglês no Brasil é pautado no princípio norteador presente na Lei de Diretrizes e Bases da Educação Brasileira n. 9394/1996 (LDB), nas propostas dos Parâmetros Curriculares Nacionais (PGN) e na discussão sobre métodos de ensino da língua inglesa, que se alia ao interesse no aprendizado de uma língua estrangeira.

A participação dos discentes de língua inglesa, do Programa Institucional de Bolsa de Iniciação à Docência (PIBID), da Universidade Federal do Rio Grande do Norte (UFRN), mostra-se essencial para os alunos da escola estadual Instituto Ary Parreiras. Pelas observações realizadas, percebemos que os alunos estão cada vez mais motivados a melhorar no aprendizado da língua estrangeira. Mesmo que eles já tivessem incentivos, sempre existe a curiosidade pelo novo. A cada aula, os alunos da escola exploram e buscam novos conhecimentos e encontraram, nos bolsistas do programa, diferentes formas de aprendizagem que dialogam com os conteúdos do componente curricular de língua inglesa.

Este artigo propõe uma reflexão sobre motivação no ensino de língua inglesa, no ensino fundamental da escola pública, por meio da oralidade. Tem como objetivos específicos: identificar como a motivação pode afetar positivamente o rendimento da aprendizagem dos alunos; relacionar as diferentes formas de abordagens indutivas de ensino com a produção oral na aprendizagem; e, avaliar a aprendizagem dos alunos.
A intervenção dos bolsistas do PIBID no Instituto Ary Parreiras causou curiosidade nos alunos em relação ao idioma não tão desconhecido e estímulo ao participar nas aulas comunicativas de inglês. Os alunos queriam saber quais seriam as melhorias para a sala de aula e para o aprendizado da língua inglesa. Assim, eles foram apresentados as mais diversas situações de oralidade com o uso do idioma, puderam superar o medo e perceber uma forma diferente para dar continuidade ao seu aprendizado.

Os alunos mostraram sede de conhecimento necessária para o aprendizado da língua inglesa, e mesmo com dificuldades, praticaram a pronúncia, a escrita e até desenvolveram o hábito de ouvir no outro idioma, uma vez que as aulas, orientações e instruções eram feitas em inglês.

Com as aulas mais focadas na comunicação entre os alunos, bolsistas e o professor, em língua inglesa, um dos desafios enfrentados, relacionado às dificuldades de compreensão, referiu-se aos assuntos mais abstratos, com características mais peculiares dos falantes da língua inglesa. Dessa forma, buscou-se apresentar diferentes maneiras de expor variados assuntos de forma lúdica, por meio da linguagem corporal e que a aprendizagem acontecesse de forma indutiva, com foco no reconhecimento do que era estudado pelo aluno. Outro desafio refere-se aos materiais utilizados em sala de aula. Mesmo com a ausência de recursos tecnológicos na escola, o ensino e a aprendizagem não foram afetados.

\section{MÉTODO}

As observações foram feitas em uma turma de $8^{\circ}$ ano do ensino fundamental, com 22 alunos participantes, que serviu de base para a análise do artigo. As aulas, que tinham duração de 50 minutos e uma frequência de duas vezes por semana, ocorreram no período compreendido entre o terceiro e o quarto bimestre do ano letivo de 2016. Uma dessas aulas era usada pelo professor da turma para a explicação de todo o conteúdo, com o intuito de "mobilizar conhecimentos prévios dos alunos acerca do vocabulário pertinente ao assunto da conversa, além de enfatizar a instrução explícita de conversation starters como forma de tornar a 
interação natural" (DONNINNI, 2010, p. 67). Posteriormente a essa exposição dos alunos, eles iriam estudar, já com o conhecimento prévio, na aula seguinte, com a intervenção dos bolsistas do PIBID. Durante essa aula, os alunos eram expostos às formas mais lúdicas de aprender, como: jogo da forca, mímica, imagem e ação, entrevistar o colega de sala, interpretar papéis, atuar, entre outras formas dinâmicas para fixar o conteúdo já estudado. Os bolsistas ficaram responsáveis pela parte da dinamização do conteúdo, ao trabalhar os jogos lúdicos nos quais exploravam a cooperação entre os alunos e o professor.

A aula era planejada com antecedência e baseava-se no modelo de referência de organização das sequências de atividades conhecido como Presentation, Practice, Production (PPP). De acordo com Donnini (2010), o modelo PPP está associado ao plano de aula (lesson plan) e a uma "concepção de aprendizagem como aquisição de comportamentos" (DONNINI, 2010, p. 46). Segundo esse modelo, uma aula eficiente segue três momentos: o momento da apresentação, em que o professor utiliza um recurso didático e introduz o conteúdo para os alunos; o momento da prática, no qual algumas atividades são realizadas com o intuito de exercitar o conteúdo que foi introduzido; e por fim, o momento da produção, em que os alunos fazem atividades nas quais eles podem personalizar o conteúdo aprendido, por meio de simulações, resoluções de problemas, troca de opiniões.

A empolgação dos alunos nas aulas evidenciava-se quando eles eram convidados a participar, a falar ou a demonstrar algo para seus colegas, como durante um jogo de mímica, quando eles ficavam responsáveis por ensinar e aprender, de forma que tinham que passar o que aprenderam para seus colegas, usando apenas movimentos corporais.

Com a explicação do conteúdo oferecida pelo professor, em português, no momento em que os alunos já tinham a base desse conteúdo sobre gramática, os bolsistas se comprometiam a falar apenas em inglês, na sala de aula. Em alguns momentos, era solicitado que os alunos criassem algumas frases com o conteúdo apresentado e, ao final de cada aula, eles liam o que tinham escrito em voz alta, praticando assim sua oralidade, além disso, eles eram motivados a repetir em voz alta, de forma correta, o que era apresentado pelos bolsistas.

O fator motivação, ao qual esse artigo se propôs a descrever como principal elemento no interesse e a participação dos alunos em aulas focadas na oralidade da língua inglesa, é descrito como "um fator interno que dá início, dirige e integra o comportamento de uma pessoa" (MURRAY, 1986, p. 20). Para Garrido (1990) a motivação é um processo psicológico, que a partir de uma força originada no interior do indivíduo, impulsiona a uma ação. "Os motivos ativam e despertam o organismo, dirigem-no para um alvo em particular e mantém o organismo em ação" (GARRIDO, 1990, p. 112).

Dessa forma, Gardner (1985) apresenta o indivíduo motivado como sendo aquele que quer realizar um objetivo em particular, esforça-se para alcançá-lo e demonstra satisfação nas atividades propostas para a realização de uma meta. Dentro do projeto desenvolvido na escola, a motivação foi encorajada pela fantasia dos alunos estarem na presença de falantes nativos da língua inglesa e, dentro dessa fantasia, por esses "nativos" não compreenderem a língua portuguesa, criou-se a necessidade de comunicarem-se em inglês.

De acordo com Parente (2013), ao citar Bergmann (2002), considerando a definição de motivação, existe a separação entre motivação extrínseca e motivação intrínseca. A motivação extrínseca como sendo fatores externos ao aluno, como o ambiente escolar e a maneira na qual o tópico é apresentado em sala de aula. Dessa forma, a motivação extrínseca fica sob responsabilidade do professor, que deve apresentar o tópico a ser estudado da forma mais atraente possível. 
A motivação intrínseca diz respeito a fatores que vem de dentro do aluno, sua identificação com o inglês, sua determinação em aprender algo novo e seu interesse em participar de forma ativa do processo de aprendizagem. Assim, a motivação intrínseca se configura como a mais complexa de impulsionar, pois parte do íntimo do aluno e o professor, por mais que tente, pouco pode fazer diante desse fator. Contudo, em nosso artigo, o professor

\section{RESULTADOS PRELIMINARES:}

Os resultados apresentados, ainda preliminares, foram pautados na comparação entre as notas gerais do segundo bimestre (representadas pela linha de cor azul no gráfico 01), período em que o PIBID ainda não atuava na escola, e as notas das provas do terceiro bimestre (representadas pela linha de cor laranja no gráfico 01), período em que o PIBID começou com as intervenções. As notas são representadas pelo eixo vertical, de $0 \mathrm{a}$ 10, ao passo que as letras de A a X, representadas e os bolsistas buscaram impulsionar a participação dos alunos interferindo no exterior, fazendo relação do que era estudado com a vida cotidiana dos alunos e trazendo para as aulas atividades de interação, de movimento (jogos e dinâmicas em grupo), e diálogos, buscando também impulsionar o interior, proporcionando aos alunos o contato com estrangeiros, forçando-os, assim, a utilizarem a língua inglesa.

pelo eixo horizontal, referem-se aos 22 alunos que fizeram parte do corpus.

O gráfico mostra resultados positivos, ainda que bem incipientes. $\mathrm{O}$ aumento na nota ficou dentro de décimos, ou um ponto, porém já reflete um avanço diante do que foi apresentado. Embora o resultado seja discreto, levando em consideração que esse trabalho que continuará, espera-se que haja um maior resultado e evolução das notas com o passar do ano letivo.

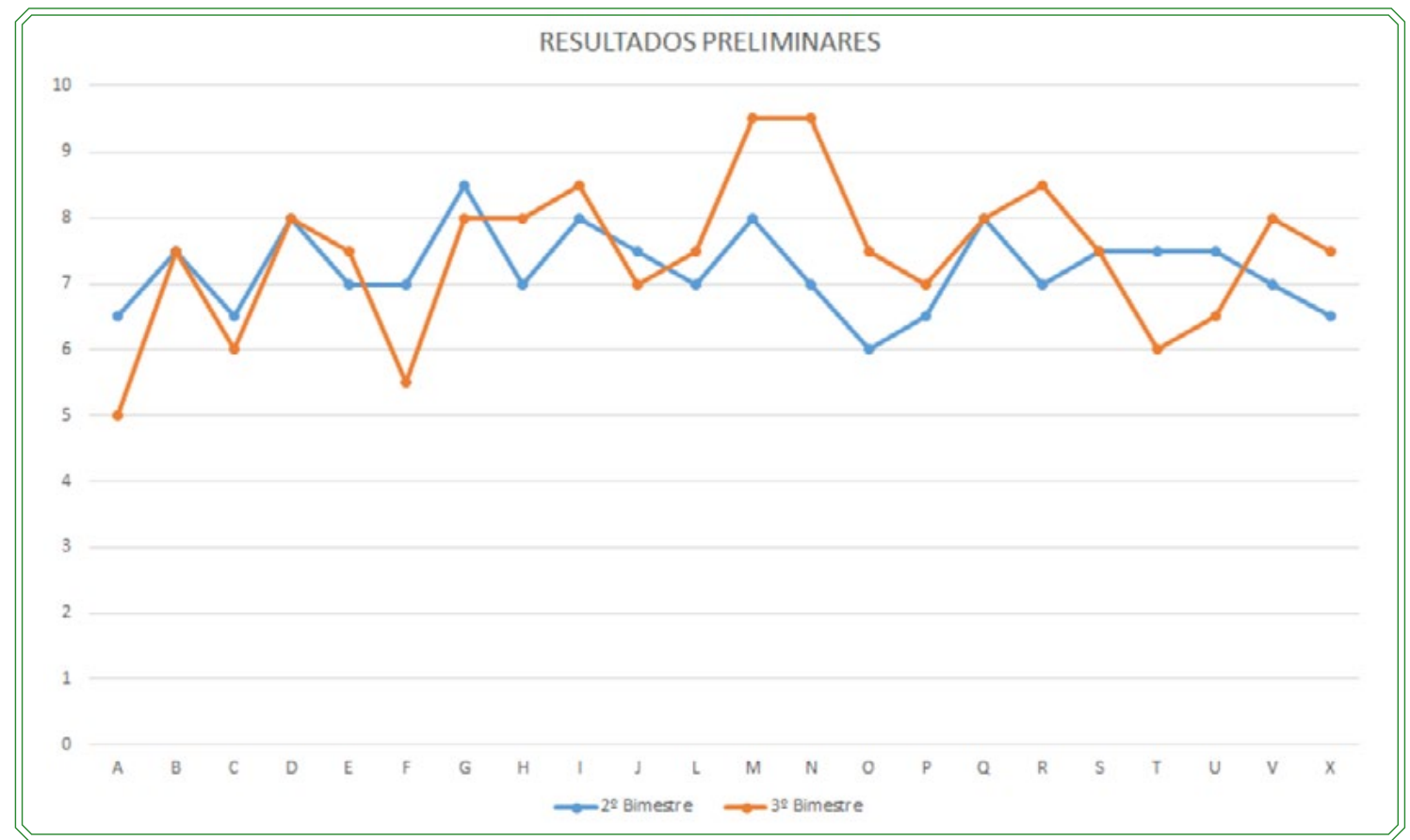

Gráfico 01 - Resultados preliminares (notas dos 22 alunos do $2^{\circ}$ e $3^{\circ}$ bimestres)

Fonte: Autoria própria. 
É importante ressaltar que não se consegue atingir todos os alunos da mesma forma, mesmo que seja proporcionando um ambiente em que eles se sintam confortáveis e que os conteúdos didáticos que serão usados em seu dia a dia sejam mostrados diante da necessidade da língua inglesa. Os alunos de escola pública vivem uma realidade que pode influenciar, negativamente, no processo de aprendizagem. Essa realidade não se refere apenas ao ensino-aprendizagem, mas a vivência com os colegas, a violência da comunidade na qual a escola está inserida, a ausência de profissionais que possam cuidar do lado psicológico quando o problema é familiar, entre outros fatores. O importante é fazer com que todos possam participar das atividades propostas, sejam expostos à mesma realidade de oportunidades e, com o tempo, os resultados melhoram com uma participação maior dos alunos.

\section{CONSIDERAÇÕES FINAIS}

Diante de tudo o que foi exposto neste artigo, a descrição dos resultados preliminares mostra que, por meio da motivação, pode-se desenvolver, nos alunos da educação básica da escola pública, as habilidades necessárias para uma fluência na língua inglesa.

O engajamento dos alunos nas aulas evidencia que a fuga do ensino tradicional, pautado nas normatizações da gramática e com o foco no professor e não no aprendizado do aluno, quebra obstáculos no processo de aprendizagem da língua inglesa. Por mais que as formas de avaliações, como provas e testes, sejam tradicionais, pode-se quantificar a evolução do aluno no processo do desenvolvimento, não só na habilidade escrita, mas também na habilidade oral.

Mesmo sabendo que o conteúdo absorvido pelos alunos é importante, durante as aulas, e diante da realidade em que eles vivem, é difícil não se preocupar com o resultado obtido nos exames avaliativos, pois sabe-se que faz parte do sistema. Dentro desse sistema, uma nota julga todo o conhecimento absorvido durante o bimestre e o ano letivo. No caso desse artigo, as notas serviram para quantificar e apresentar uma visão geral da situação após as aulas com foco na comunicação oral em língua inglesa.

Observamos que, por meio da motivação, os alunos fixaram os conteúdos e demonstraram na produção das atividades orais que recordavam do que foi ensinado, assim como souberam demonstrar também o conhecimento desse conteúdo na prova escrita.

Este artigo serve de ponto de partida para uma preocupação futura com o ensino da língua inglesa, com foco em teorias comunicativas, pois, em dois bimestres, observamos uma melhora nas atitudes perante as atividades orais e nos resultados das avaliações escritas. A tendência dessa turma que teve a oportunidade de se motivar com as aulas, com foco na oralidade, é de que o ano letivo tenha terminado com resultados melhores e mais notáveis do que os aqui apresentados. 


\section{MOTIVATION THROUGH SPEAKING IN THE PROCESS OF ENGLISH LANGUAGE LEARNING}

\section{ABSTRACT}

This paper intends to ponder about the motivation towards practicing English oral activities in a public school, the use of games and fun activities as a way to stimulate the students' participation on the class. The classes were observed and taught by the students in a scholarship program called "Programa Institucional de Bolsa de Iniciação à Docencia (PIBID)", at Ary Parreiras State school, Alecrim, Natal - RN, during the second half of 2016. The purpose was to assist students' comprehension of the topics in English previously studied. We made use

of fun activities focused on speaking and listening comprehension. The students had to interact and cooperate with each other so that all of them, including the shy ones, could participate in the activities. It was possible to observe an improvement of the students' interests in English as well as an improvement in their participation in class, which are direct consequences of motivation.

Key-words: Motivation. PIBID. Brazilian public school. English learning and teaching. Speaking skills.

\section{REFERÊNCIAS}

BERGMANN, Juliana Cristina Faggio. Aquisição de uma língua estrangeira: o livro didático como motivador. 2002. 163 f. Dissertação (Mestrado em Letras) - Universidade Federal do Paraná, Curitiba, 2002.

DONNINI, LÍVIA. Ensino de língua inglesa. São Paulo: Cengage Learning, 2010.

GARDNER, R.C. Social Psycology and second language learning: the role of attitudes and motivation. London: Edward Arnold, 1985.

GARRIDO, I. Motivacion, emocion y accion educativa. In: MAYOR, L.; TORTOSA, F. (Ed.) Âmbitos de aplicacion de la psicologia motivacional. p. 284-343. Bilbao: Desclee de Brower, 1990.

MURRAY, E. J. Motivação e emoção. Rio de Janeiro: Guanabara-Koogan, 1986.

PARENTE, Maisa Coelho; SCHNEIDER, Márcia Sueli P. A motivação e/ou a desmotivação na aula de língua inglesa dos alunos do $9^{\circ}$ ano: um estudo de caso. In: SIMPÓSIO NACIONAL E INTERNAGIONAL DE LETRAS E LINGUÍSTICA, 1, 2013, Uberlândia. Anais... Uberlândia: EDUFU, 2013

SIQUEIRA, Luciana Gurgel Guida; WECHSLER, Solange M. Motivação para a aprendizagem escolar: possibilidade de medida. Aval. psicol., Porto Alegre, v. 5, n. 1, p. 21-31, jun. 2006. 